\title{
Evaluating and Optimizing Fish Health and Welfare During Experimental Procedures
}

\author{
Nicola Goodwin,,2 Lynda Westall, ${ }^{1,}$ Natasha A. Karp, ${ }^{3}$ Diane Hazlehurst, ${ }^{1}$ Ceri Kovacs, \\ Rosemary Keeble, ${ }^{2}$ Peter Thompson, Richard Collins, and James Bussell ${ }^{1}$
}

\begin{abstract}
Many facilities house fish in separate static containers post-procedure, for example, while awaiting genotyping results. This ensures fish can be easily identified, but it does not allow for provision of continuous filtered water or diet. At the Wellcome Trust Sanger Institute, concern over the housing conditions led to the development of an individual housing system (GeneS) enabling feeding and water filtration. Trials to compare the water quality measures between the various systems found that fish housed in static containers experienced rapid deterioration in water quality. By day 1, measures of ammonia were outside the Institute's prescribed values and continued to rise until it was 25 -fold higher than recommended levels. Nitrite levels were also outside recommended levels for all fish by day 9 and were twofold higher by the end of the trial. The water quality measures for tanks held on the recirculating system were stable even though food was provided. These results indicate that for housing zebrafish, running water or appropriately timed water changes are a critical component to ensure that the ethical obligations are met.
\end{abstract}

\section{Introduction}

I $\mathrm{N}$ RECENT YEARS, zebrafish have joined the mouse as an important model organism to study biological processes in vivo. ${ }^{1}$ This is due to their high fecundity, small size, rapid development, and generation time, as well as providing optical transparency during embryogenesis. ${ }^{2}$ Furthermore, the zebrafish genome ${ }^{3}$ has been sequenced and annotated to a very high standard only comparable to the human and mouse genome. While there is considerable literature available with regard to the use of zebrafish in research, there is still limited information in terms of their husbandry requirements.

Due to the relative ease in maintaining zebrafish stocks and their tolerance of a wide range of water parameters, captive zebrafish are considered a hardy species. While this may make production and maintenance fairly straightforward, it can potentially lead to poorly controlled experiments by changing the development, reproduction, and immune capacity of the fish due to stress. ${ }^{4}$ In addition, variation of the environment within a laboratory potentially increases variance, which will decrease the sensitivity of experiments or if poorly controlled will lead to confounded experiments. Furthermore, as with all animal experiments, there is an ethical responsibility to ensure that the housing and husbandry of animals during the life of the experiment are reviewed and that animal welfare standards are adhered to to minimize stress.

The Code of Practice for the Housing and Care of Animals Bred, Supplied, or Used for Scientific Purposes (COP) states that, "Adequate water supply of suitable quality shall be provided at all times" and that "water flow in re-circulatory systems or filtration within tanks shall be sufficient to ensure that water-quality parameters are maintained within acceptable levels". 5 Unfortunately, the COP does not state the specific zebrafish requirements for water quality. Following a literature review (Table 1), the Wellcome Trust Sanger Institute (WTSI) has collated these measures to define specific zebrafish water quality values (Table 2 ).

For critical water quality measures, Table 2 details the current WTSI-recommended acceptable ranges of water quality measures for zebrafish. These were selected following an extensive literature review (Table 1). A slightly higher $\mathrm{pH}$ $(\mathrm{pH} 7.2-7.6)$ has been recommended by Varga ${ }^{11}$ to support the denitrifying bacteria in the filtration system and reduce ammonium. However, within the WTSI, no $\mathrm{pH}$ fluctuations

\footnotetext{
${ }^{1}$ Research Support Facility, Wellcome Trust Sanger Institute, Cambridge, United Kingdom.

${ }^{2}$ Department of Medicine, MRC-LMB, Cambridge University, Cambridge, United Kingdom.

${ }^{3}$ Mouse Informatics Group, Wellcome Trust Sanger Institute, Cambridge, United Kingdom.
}

(C) Nicola Goodwin et al., 2016; Published by Mary Ann Liebert, Inc. This Open Access article is distributed under the terms of the Creative Commons License (<http://creativecommons.org/licenses/by/4.0 $>$ ), which permits unrestricted use, distribution, and reproduction in any medium, provided the original work is properly credited. 
Table 1. Literature Review of Acceptable Ranges for Various Water Quality Measures

\begin{tabular}{|c|c|c|}
\hline Parameters & Acceptable range & Author/website/book \\
\hline \multirow[t]{6}{*}{ Ammonia $\left(\mathrm{NH}_{3}\right)$} & $\begin{array}{l}<0.5 \mathrm{mg} / \mathrm{L} \text { (lethal limit) } \\
0.02-0.05 \mathrm{mg} / \mathrm{L} \\
\quad \text { (sublethal poisoning } \\
\text { can occur) }\end{array}$ & $\begin{array}{l}\text { Essential Zebrafish Methods: Genetics and Genomics: } \\
\text { Genetics and Genomics } 6\end{array}$ \\
\hline & $<0.02 \mathrm{mg} / \mathrm{L}$ & $\begin{array}{l}\text { Water Quality Criteria } \\
\text { Ornamental Aquatic Trade Association }{ }^{7}\end{array}$ \\
\hline & $<0.02 \mathrm{mg} / \mathrm{L}$ & An Introduction to Water Chemistry in Freshwater Aquaculture ${ }^{8}$ \\
\hline & $<0.05 \mathrm{mg} / \mathrm{L}$ & Fish Disease: Diagnosis and Treatment ${ }^{9}$ \\
\hline & $<0.01 \mathrm{mg} / \mathrm{L}$ & Ammonia Toxicity in Teleost Fishes: A Review ${ }^{10}$ \\
\hline & $<0.05 \mathrm{mg} / \mathrm{L}$ & $\begin{array}{l}\text { The Zebrafish: Genetics, Genomics and Informatics: Genetics, Genomics } \\
\text { and Informatics }\end{array}$ \\
\hline \multirow[t]{3}{*}{ Nitrite $\left(\mathrm{NO}_{2}^{-}\right)$} & $<0.10 \mathrm{mg} / \mathrm{L}$ & $\begin{array}{l}\text { Essential Zebrafish Methods: Genetics and Genomics: Genetics and } \\
\text { Genomics } 6\end{array}$ \\
\hline & $<0.10 \mathrm{mg} / \mathrm{L}$ & Fish Disease: Diagnosis and Treatment ${ }^{5}$ \\
\hline & $<0.5 \mathrm{mg} / \mathrm{L}$ & $\begin{array}{l}\text { The Zebrafish: Genetics, Genomics and Informatics: Genetics, Genomics } \\
\text { and Informatics }\end{array}$ \\
\hline \multirow[t]{2}{*}{ Conductivity } & $500-2000 \mathrm{mg} / \mathrm{L}$ & $\begin{array}{l}\text { The Zebrafish: Genetics, Genomics and Informatics: Genetics, Genomics } \\
\text { and Informatics }\end{array}$ \\
\hline & $500-2000 \mathrm{mg} / \mathrm{L}$ & The Laboratory Zebrafish ${ }^{12}$ \\
\hline \multirow[t]{3}{*}{$\mathrm{pH}$} & $6.8-8.5$ & The Laboratory Zebrafish ${ }^{12}$ \\
\hline & $\begin{array}{l}7.0-8.0 \text { (for optimal } \\
\text { egg production) }\end{array}$ & Essential Zebrafish Methods: Cell and Developmental Biology ${ }^{13}$ \\
\hline & $7.2-7.6$ & $\begin{array}{l}\text { The Zebrafish: Genetics, Genomics and Informatics: Genetics, Genomics } \\
\text { and Informatics }\end{array}$ \\
\hline \multirow[t]{4}{*}{ Temperature } & $26-28^{\circ} \mathrm{C}$ & Howells and Betts ${ }^{14}$ \\
\hline & $25-28^{\circ} \mathrm{C}$ & Zebrafish $^{15}$ \\
\hline & $24-28^{\circ} \mathrm{C}$ & The Laboratory Zebrafish ${ }^{12}$ \\
\hline & $16-32^{\circ} \mathrm{C}$ & $\begin{array}{l}\text { The Zebrafish: Genetics, Genomics and Informatics: Genetics, Genomics } \\
\text { and Informatics }\end{array}$ \\
\hline
\end{tabular}

have been identified to necessitate the change in WTSI housing (see "Results" section).

At the WTSI Research Support Facility, we have the capacity for $5678(1-8 \mathrm{~L})$ tanks within the aquatic area to support the various research programs within the institute. The zebrafish research is dominated at the institute by the Zebrafish Mutation Project, which is a high-throughput program determining the relationship between gene function and disease. During this program, 200,000 zebrafish have been genotyped by removing a small section of tissue from their caudal fin. Following this procedure, each fish was then transferred into a small static container (Fig. 1A, B) until their genotype had been established. During this process, the fish were not fed to maintain water quality. The genotyping process on average took 5 days or less (Supplementary Fig. S1; Supplementary Data are available online at www.liebertpub.com/zeb), however, if it exceeded 14 days, then the fish were returned to their home tanks and the genotyping process repeated.

Table 2. Wellcome Trust Sanger Institute Water QUALITY REQUIREMENTS FOR ZEBRAFISH

\begin{tabular}{lc}
\hline Water component & Acceptable ranges \\
\hline Ammonia $\left(\mathrm{NH}_{3}-\mathrm{N}\right)$ & $0.0-0.10 \mathrm{mg} / \mathrm{L}$ \\
Nitrite & $0.0-0.10 \mathrm{mg} / \mathrm{L}$ \\
$\mathrm{pH}$ & $7.0 \pm 0.3$ \\
Conductivity & $600 \pm 50 \mu \mathrm{s}$ \\
Temperature & $26 \pm 2^{\circ} \mathrm{C}$ \\
\hline
\end{tabular}

A review of this experimental procedure identified a number of areas that could contribute to the fish experiencing stress during the procedure. The majority of the concerns focused on issues arising from the static water; the fish cannot be fed, there is no enrichment, and there are potential issues with declining water quality. Furthermore, the fish cannot easily be observed for the essential welfare monitoring steps due to the stacking of the containers. With smaller scale studies, static containers can be avoided by housing fish individually on the main system with filtered water flow, while inefficient in terms of space this avoids the potential stress issues.

The use of static containers over a limited time period has been an acceptable procedure within the United Kingdom animal welfare remit. After identifying concerns, the Sanger Institute initiated a project to investigate alternate solutions for housing zebrafish during procedures that require the fish to be held singly for identification. Commercially, the Sanger Institute found that one other system existed (DC-96, www.randaquatics.com); however, this was not suitable as it was incompatible with the established aquatic racking systems at the institute and did not allow for removal of individual containers. An inability to remove individual containers would require the fish to be removed by nets rather than pouring, which is a more stressful way of handling the fish. As a result, the institute looked to develop a custommade system and identified critical design features needed (Supplementary Table S1). In collaboration with Tecniplast (Aquatic Solutions), a pilot system was developed, tested, and refined to provide the GeneS system (http://tecniplast.it/us/ 
A
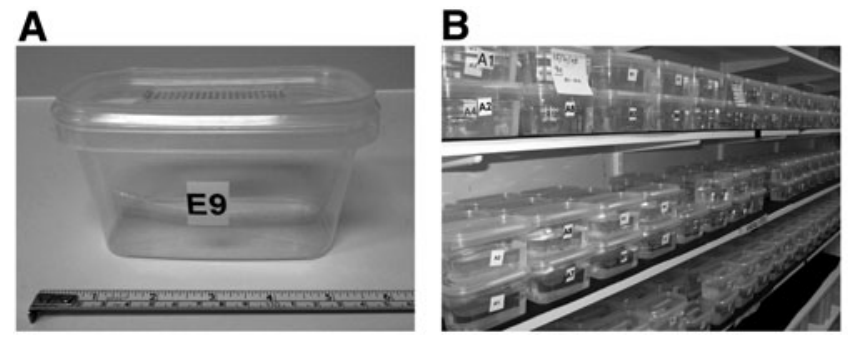

catalog/fish-tanks.html) (Fig. 1C). This custom-made system was not only optimized for animal welfare but also ergonomic considerations and procedural throughput.

Trials were then conducted to assess water quality measures when zebrafish were housed in a static system and compared to the GeneS system with and without feeding. The experiments found that water quality during the static procedure was severely compromised and this rapidly occurs during the time in which the fish are held in these containers. As such, whatever systems are used for housing zebrafish, running water or frequent/timely water changes are a critical component to ensure that our ethical obligations are met.

\section{Materials and Methods}

\section{Ethics}

The care and use of zebrafish in the WTSI study was carried out in accordance with the United Kingdom Home Office regulations, United Kingdom Animals (Scientific Procedures) Act of 1986 under a United Kingdom Home Office licence, which approved this work (70/7606). All efforts were made to minimize suffering by considerate housing and husbandry. Animal welfare was assessed routinely for all fish involved by daily visual inspection assessing for abnormal behavior and appearance. Adult zebrafish were culled by the approved method of overdose of an anesthetic by immersion in a terminal anesthesia (MS222).

\section{Study design}

Three housing scenarios were compared using singly housed wild-type fish ( $n=5 /$ system) of the Tupfel Long Fin strain for 9 days. Water quality $(\mathrm{pH}$, conductivity, temperature, ammonia, and nitrite) was monitored during the study. The three systems comprised the following: static containers non-fed (controls), GeneS fed, and GeneS non-fed. The fish were randomly selected from a colony tank with all fish being between 6 and 8 months of age and of both sexes. Water samples were taken 1 day before fish were added and then on days $1,3,6$, and 9. Water samples were taken from each container between 08.30 and 16.30 each day of the trial. Welfare checks were performed when the lights came on and before leaving at the end of the day. Additional static containers were set up to replace those where fish were found dead during normal daily welfare checks (two died on day 1 for the static system and 1 on day 9). However, this is not unexpected as the number found dead falls within the rate experienced for the background of this stock when housed within a static system. Originally, the trial was going to run for 13 days to reflect the fact that the static container procedure can be used for this period; however, the study was halted early due to the poor water quality measures in the static containers.

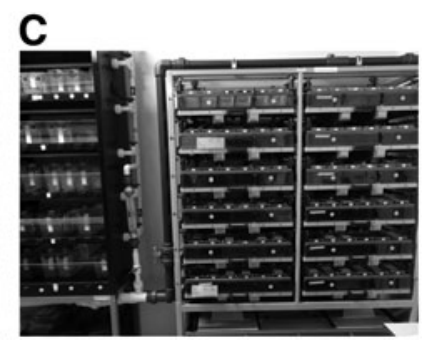

FIG. 1. Static pot system used during the genotyping procedure. (A) Image of one pot. (B) Image showing the scale of implementation at the Wellcome Trust Sanger Institute. (C) Image of the genes rack on system.
To validate the observed changes in water quality seen in the static system and to remove the potential impact of repeated sampling on the water quality, the study was repeated for the static system by an additional trial. In this, 36 containers were set up to allow random selection of six containers at each time point to ensure containers were only sampled once during a 14-day period.

\section{Housing conditions}

All fish were raised and held within the WTSI Research Support Facility where the environment is controlled with a temperature of $24 \pm 2^{\circ} \mathrm{C}$, humidity $45 \pm 10 \%$, and a 15 -h light/ 9-h dark/light cycle.

The GeneS polycarbonate tanks measuring $145 \times 90 \times 85 \mathrm{~mm}$ $(\mathrm{L} \times \mathrm{W} \times \mathrm{D}$ max) (volume of water $370 \mathrm{~mL}$ on system) were held within a specifically designed GeneS rack, which was connected to the facilities recirculating the Z-Mod system (Marine Biotech) containing $\sim 10,000 \mathrm{~L}$ of water. The conditions within the GeneS rack are therefore the same as the recirculating system. System water entering the GeneS tanks was prefiltered through fine and coarse meshed filtration pads before entering a prefilter cartridge system containing carbon pellets and 4:100 w UV irradiation tubes (MBK installations Ltd.). Ten percent of system water was automatically drained from the systems reservoir and replaced once per day with reverse osmosis (RO) water. During the study, the water quality of the Marine Biotech system was maintained within the following ranges: temperature $26 \pm 2^{\circ} \mathrm{C}, \mathrm{pH} 7 \pm 3$, and conductivity of $600 \pm 50 \mu \mathrm{s}$. The plastic static containers measuring $140 \times 95 \times 95(\mathrm{~L} \times \mathrm{W} \times \mathrm{D})($ volume of water $450 \mathrm{~mL})$ were held on a free standing rack within the same room as the GeneS rack; as standard procedures were followed, no water changes occurred.

\section{Feeding regimen}

Fish held in 12 GeneS tanks for the fed group were fed twice per day with Artemia (non-decapsulated premium brine shrimp 260 grade from ZM Systems). These were cultured by using the following method: $50 \mathrm{~mL}$ of Artemia cysts were left to hatch for $36 \mathrm{~h}$ in a $10-\mathrm{L}$ hatching cone containing $8 \mathrm{~L}$ of RO water and $150 \mathrm{~mL}$ of artificial sea salt. Artemia were manually filtered to remove any waste and salt solution before being provided to the adults twice a day, using a $500-\mathrm{mL}$ squirt bottle to deliver $\sim 3 \mathrm{~mL}$ of Artemia per tank.

\section{Water sampling}

The daily sampling consisted of $10 \mathrm{~mL}$ of system water being removed per container, per test (two tests in total: nitrite and ammonia). These samples were taken by removing the lid of each container and pipetting the required volume. The $10 \mathrm{~mL}$ 
samples were then placed into the portable readers (HI-96707 portablenitrite photometer[http://hannainstruments.co.uk/nitritemeter-with-cal-checkr.html] and HI-96700 Ammonia Portable Photometer, Low Range [HI-96700] [http://hannainstruments .co.uk/ammonia-ion-specific-meter-supplied-with-2 -cuvetsand-caps.html]). Conductivity, $\mathrm{pH}$, and temperature were taken by placing the relevant probes (HI-9124N $\mathrm{pH}$ and temperature Meter [http://hannainstruments.co.uk/ph/meters/ handheld-ph-meter-with-enhanced-design.html] and HI-9033 H Multi-Range Conductivity Meter [http://hannainstruments .co.uk/handheld-water-resistant-multi-range-conductivity-meter .html]) within the containers until a stable reading was achieved.

\section{Statistical methods}

A pilot study had assessed the variation in water quality measures of interest and with the high reproducibility observed and the goal of detecting large changes (to be outside the acceptable threshold) it was deemed 5 experimental units per study would suffice. Data were summarized with Excel using standard formulas and the number of readings at each time point that were outside the acceptable limits assessed. For the first study, the concentrations measured were adjusted for the reduced volume associated with the repeated sampling using the dilution equation $\left(\mathrm{C}_{1} \mathrm{~V}_{1}=\mathrm{C}_{2} \mathrm{~V}_{2}\right)$. The experimental unit in these studies is the individual housing system.

\section{Results}

The water quality measures, for the GeneS system both with and without feeding, showed that a recirculating system led to stable water quality measures that were not affected by the additional step of feeding (Supplementary Fig. S2). The
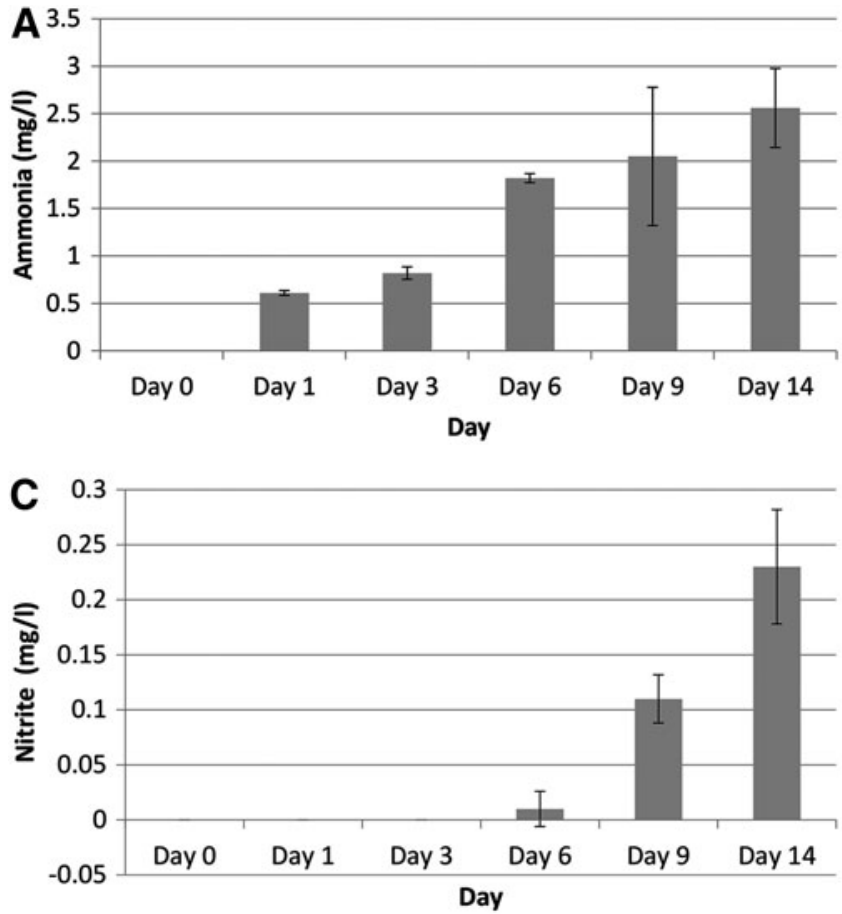

studies of water quality in the static system in contrast found that there was a rapid decrease in water quality, in particular, there was an increase in the ammonia concentration (Supplementary Fig. S2; Supplementary Table S2 and Fig. 2). During the validation study, the onset of the water quality deterioration was such that by day 1 , the ammonia concentration was outside the acceptable values as determined from the literature and by day nine 4 of the 6 nitrite readings. By day 14, the average ammonia level was 25-fold higher than the acceptable level and the nitrite level two-fold higher (Fig. 2).

\section{Discussion}

For many years, we have used the static housing system within the institute with the argument that omitting the feeding step would prevent the degradation of water quality. Testing this assumption finds that it was not valid. The results give strong evidence that a static system for housing zebrafish will lead to rapid degradation of conditions into unacceptable levels outside those considered acceptable.

Visual monitoring of the fish during the use of static containers at the WTSI has, to date, not raised any ethical concerns as the fish were active, showing normal behavior and without loss in color or other behavioral indicators of stress. Before this trial, the majority of fish were held in static containers for 5 days or less (Supplementary Fig. S1), where we now find that levels of ammonia are typically more than eight-fold higher than the acceptable limits. This raises the question as to whether the ammonia threshold is too stringent and the fish can tolerate a wider margin. This, however, would not help the genotype processing, which needs storage of up to 14 days. More extensive testing would be needed to assess whether the thresholds could be relaxed.
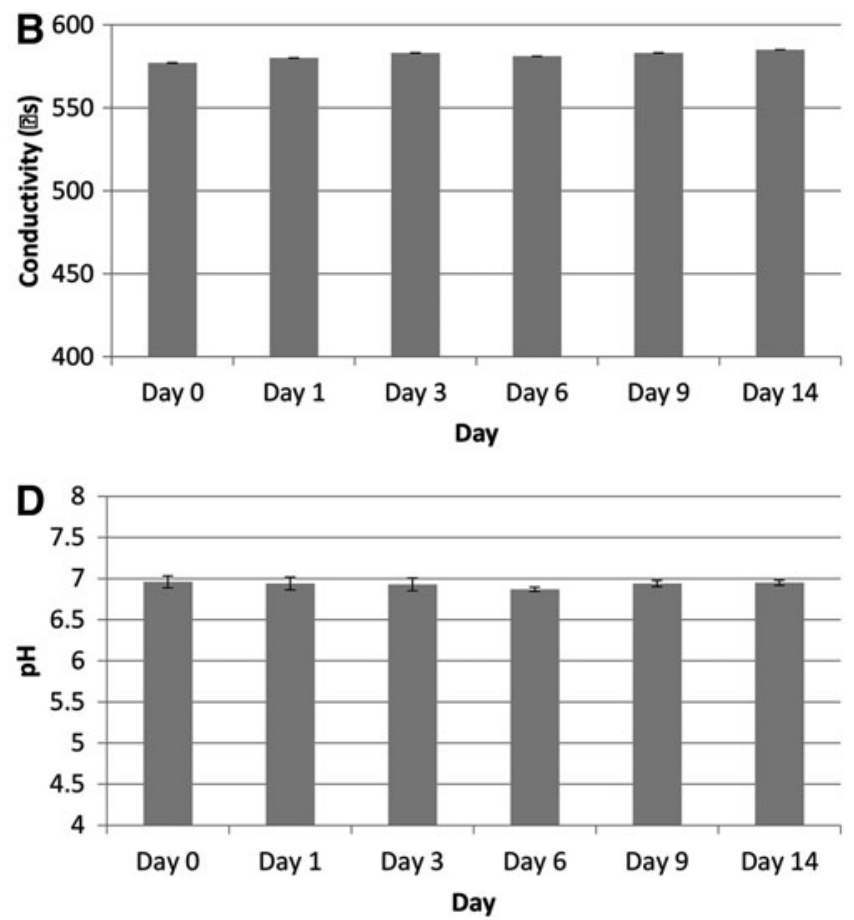

FIG. 2. Water quality measure for the static system. Water quality measures obtained during the validation study where six readings were collected at each time point. The graphs are a plot of the mean reading with standard deviation error bars. The graphs show (A) ammonia, (B) conductivity, (C) nitrite, (D) $\mathrm{pH}$. 
Introducing water flow not only addressed the water quality issue but also allows for live feeding, which encourages natural chasing behavior, thereby also providing environmental enrichment to the animals. The improved water quality measures allow the fish to remain in their isolation tanks beyond the current 14-day cutoff increasing the efficiency of the procedure.

This article compares the best and worst housing conditions: flowing versus static water. Addressing the rapid deterioration in water quality measures is required to meet our ethical obligation; however, there are potential scenarios where housing systems with flow are not available to researchers. An alternative strategy would be to change the water daily while fish are housed in a static system. This strategy is more labor-intensive and potentially more stressful to the fish through the additional handling, however, it would maintain the water quality measures closer to the acceptable ranges.

Researchers and animal caretakers alike have an ethical and a research outcome-based interest to maintain the most optimal animal welfare conditions during and between experiments. The results of this study into holding conditions during isolation of individual fish suggest that running water or frequent water changes, which also allow for continued feeding, significantly reduce ammonia build-up, provide some environmental enrichment, and therefore improve the welfare of animals that need to be kept isolated for short and intermediate experimental periods.

\section{Acknowledgments}

We thank the staff from the Sanger Institute's Research Support Facility, Zebrafish Mutation Project, and Jacqui White for their support. This work was supported by the Wellcome Trust grant number 098051.

\section{Disclosure Statement}

No competing financial interests exist.

\section{References}

1. Nüsslein-Volhard C, Dahm R: Zebrafish. Oxford University Press, Oxford, 2002, pp. 1-5.

2. Lawrence $\mathrm{C}$. The husbandry of zebrafish (Danio rerio): a review. Aquaculture 2007;269:1.

3. Kettleborough R, Busch-Nentwich E, Harvey S, Dooley C, de Bruijn E, van Eeden F, et al. A systematic genome-wide analysis of zebrafish protein-coding gene function. Nature 2013;496:494-497.

4. Barton B. Stress in fishes: a diversity of responses with particular reference to changes in circulating corticosteroids. Integr Comp Biol 2002;4:517-525.

5. Home Office. (2014). Code of practice for the housing and care of animals bred, supplied. [online] GOV.UK. Available at: https://gov.uk/government/uploads/system/uploads/ attachment_data/file/388535/CoPanimalsWeb.pdf (Accessed 20 Sep. 2015).

6. Mathews JL. Common diseases of laboratory zebrafish. Essential Zebrafish Methods 2009;77:323.

7. Ornamental Aquatic Trade Association. (2008). Water quality criteria. [online] Available at: http://ornamentalfish.org/wpcontent/uploads/2012/08/Water-Quality-Criteria.pdf (accessed 20 Sep. 2015).

8. Buttner J. (2015). An introduction to water chemistry for freshwater aquaculture. [online] Northeasten regional Aquaculture Centre. Available at: http://extension.org/mediawiki/ files/7/73/Introduction_to_Water_Chemistry_for_Freshwater_ Aquaculture.pdf (Accessed 20 Sep. 2015).

9. Noga E: Fish Disease: Diagnosis and Treatment, 2nd edn. Wiley-Blackwell, Iowa, 2010.

10. Haywood GP. Ammonia toxicity in teleost fish: a review. Can Tech Rep Fish Aquat Sci 1983;1177:1-35.

11. Varga ZM: Aquaculture and husbandry at the Zebrafish International Resource Center. In: The Zebrafish: Genetics, Genomics and Informatics. Detrich HW, Westerfield M, and Zon LI (eds), pp. 458, Elsevier/Academic, Amsterdam, Netherlands, 2011.

12. Harper C, Lawrence C: The Laboratory Zebrafish. CRC Press, New York, pp. 119, 2010.

13. Grinblat Y, Sive H. Anaylsis of zebrafish development using explant culture assays. Essential zebrafish methods. Cell Dev Biol 85.

14. Howells L, Betts T. A beginner's guide to the zebrafish (Danio rerio). Anim Technol Welfare 2009;8:117-120.

15. Brand M, Nüsslein-Volhard C, Dahm R: Zebrafish. Oxford University Press, Oxford, pp. 16, 2002.

Address correspondence to: Nicola Goodwin, HNC

Department of Medicine

$M R C-L M B$

Cambridge University Cambridge CB2 OQH

United Kingdom

E-mail: ngoodwin@mrc-lmb.cam.ac.uk 